\title{
Contratos de Time-Sharing en Brasil y a Protección de los Consumidores: Crítica al Derecho Civil en Tiempos Postmodernos
}

\section{Claudia Lima Marques}

\author{
Profesora Adjunta de la Universidad Federal \\ do Rio Grande do Sul, Porto Alegre, Brasil. \\ Doctora en Derecho por la Universidad de Heidelberg, Alemania. \\ Directora Secretaria General del BRASILCON. \\ Instituto Brasileño de Política y Derecho del Consumidor.
}

\section{Introducción}

Los llamados tiempos postmodernos son un desafio para el Derecho Civil. Tiempos de esceptisismo en relación a la capacidad de la ciencia del Derecho de dar respuestas adecuadas y generales a los problemas que perturban la sociedad actual y que se modifican a una velocidad asombrosa. Tiempos de valorización de los servicios, del ocio, de lo abstracto y de lo transitorio, que acaban por decretar la insuficiencia del modelo contractual tradicional del Derecho Civil, por forzar la evolución de los conceptos del Derecho conduciendo a proponer una nueva jurisprudencia de los valores, una nueva visión de los principios del Derecho Civil, con una marcada influencia del Derecho Público y del respeto a los Derechos Fundamenrales de los ciudadanos.

En tiempos postmodernos es necesaria una visión crítica del Derecho Civil tradicional, es esencial una reacción de la ciencia del Derecho imponiendo una nueva valorización de la buena fe objetiva, como paradigma limitador de la autonomía de la voluntad, así como de los instrumentos tradicionales del Derecho Civil que pueden llevar a la opresión a los indivíduos más débiles en la sociedad. Son tiempos de pensar en la protección de la voluntad del consumidor como ideal utópico remanecente de la meta-narrativa de la modernidad. Son tiempos de alterar el punto de concentración del Derecho Civil y pensar en el grupo que recibe las declaraciones, en la confianza desperrada por la actuación profesional de los proveedores, y no únicamente en establecer normas que creen privilegios a aquel que declara, 
a aquel que redacta los contratos de masa, a aquel que impone sus métodos de marketing de venta agresivos o emotivos. L_a libertad contractual del profesional no es la única que merece protección jurídica pues su posición de poder (matchposition) en las negociaciones contractuales es clara e intrínseca a los métodos contractuales actuales, pero el Derecho debe concentrarse en la libertad del otro, en esa libertad que tiende a ser reducida, casi aniquilada, y que merece, por consiguiente, igual protección. La libertad del consumidor, su autonomía de voluntad racional y efectiva, es la que debe ser protegida. Son tiempos de relaciones contractuales multiples, impersonales destinadas a prolongarse en el tiempo y a extenderse a toda una cadena de proveedores de servicios y productos. Tiempos que imponen una visión de la obligación como un proceso mucho más complejo y duradero que una simple prestación contractual, que un dar y un hacer momentaneo entre socios contractuales teoricamente iguales, conocidos y escogidos libremente.

Segun el emérito Profesor de Filosofía del Derecho de la Universidad de ErlangenNüremberg Reinhold Zippelius el Derecho debe ser un instrumento para una organización social justa y equilibrada (zweckmässiger und gerechter Sozialgestaltung) ${ }^{1}$. De acuerdo con esta visión, las normas jurídicas son instrumentos que ayudan a determinar la realidad social, conforme los objetivos considerados justos y deseables para aquella sociedad. El Derecho puede ser, en consecuencia, un instrumento de justicia e inclusión social, de protección de determinados grupos en la sociedad, de combate al abuso del poder económico y a toda actuación de los profesionales que sea contraria a la buena fe en el intercambio entre consumidores y proveedores en el mercado.

Esta visión activa y positiva del Derecho Civil, como instrumento de combate a los males de la sociedad actual a través de la imposición de un nivel superior de respeto y lealtad en las relaciones sociales, es posible en el Brasil después de la adopción del Código de Defensa del Consumidor, ley $8.078 / 90$ que oxigenó y renovó el Derecho Civil Brasileño sin derogar el Código Civil de 1916, especificando simplemente la nueva función limitadora del principio de la buena fe y de la protección de la confianza en las llamadas relaciones de consumo.

La realidad postmoderna ${ }^{2}$ es la realidad de la postindustrialización, del postfordismo, de la tópica, del esceptisismo frente a las ciencias, frente al positivismo. época del caos, de la multiplicidad de culturas y de formas, del derecho a la diferencia, de la "enforia del

\footnotetext{
'ZIPPELIUS, Reinhold, Rechstphilosophie, 3. Ed. Beck, Munich, 1994, p. 258.

"Ver LYOTARD, Jean- François, Das Postmoderne Wissen - Ein Bericht, Peter Engeiman (Hrssg.), (Aus dem Französischen von Otto Pfersmann), Venat Passagen Veriag, 1994, p. 13: "Dieses Wort (postmodern) ist auf dem amerikanischen Kontinent, bei Saziologen und Kritikern gebräuchlich. Es bezeichnet den Zustand der Kultur nach den Transformationen, welche die Regeln der Spiele del Wissenschaft, der Literatur und der Kunste seit dem Ende des 19 Jahrhunderts getroffen haben".

"Ver Habermas, Jürgen, Nachmetaphysisches Denken, Ed. Suhrkamp, Frankfurt, 1992, p. 35.
} 
individualismo y del mercado", de la globalización y del retomo a lo tribal. Es la realidad de la substitución del Estado por las empresas particulares, de privatizaciones, del neoliberalismo, de las tercerizaciones, de la comunicación irrestricta, de la informatización y de un neoconservadurismo, de la acumulación de bienes no materiales, del desempleo en masa ${ }^{6}$, del esceptisismo sobre lo general, de un individualismo necesario, de muchas meta-narrativas simultáneas y contradictorias, de la pérdida de los valores modernos esculpidos por la sociedad burguesa y substituídos por una ética meramente discursiva y argumentativa, de legitimación por el lenguaje por el consenso momentaneo y no más por la lógica, por la razón o solamente por los valores que presenta ${ }^{7}$. Es una época de caos y de inseguridad donde las antinomias son inevitables y la desreglamentación del sistema convive con un pluralismo de fuentes legislativas y una fuerte internacionalización de las relaciones ${ }^{8}$. Es la condición postmoderna que, con la postindustrialización y la globalización de las economías, alcanza America Latina y tiene reflejos importantes en la ciencia del Derecho.

El Profesor de la Universidad de Heidelberg, Erik Jayme, consideró el contrato de time-sharing, o multipropiedad, como el modelo de contrato de la época postmoderna ${ }^{9}$. El time-sharing puede ser definido como un contrato multiple y complejo destinado a permitir la utilización habitacional de un inmueble, o de un conjunto de inmuebles, así como de los servicios conexos a esa utilización, por un cierto tiempo a cada periodo de un año ${ }^{10}$. Debido a su novedad y a su fluidez el contrato de time-sharing no es siempre comprendido por los consumidores y su multiplicación en el mercado latinoamericano está creando una serie de

"GHERST, Carlos Aberto, La posmodernidad jurídica, Buenos Aires, 1995, p. 27: "No queda pues más que añadir, la posmodemidad es también la posmoralidad, es posolidaria, es sin duda la euforia del individualismo $y$ el mercado, gobernados desde la tumba de Bentham por el nuevo perfil utilitarista, aliado al placer y a la felicidac consumista".

"Como afirma Habermas, reconocer, nombrar o denominar un fenómeno, como se hace con el postmodenisno, significa tomar suficjente distancia de él, e, inclusive, decretar su fin. Habermas no se considera postmoderno, se encuentra comprometido con los ideales de la modernidad, llega a ironizar: la frecuente utilización en la hiterarur" actual de esa denominación de "post", pero reconoce la importancia de tales pensadores como indicadores sensibles del "Zeitgeist", del pensamiento y espíritu actual, al indicar un cambio. ver HABERMAS, p. 12.

"Así la visión negativa de GHßRSI, ps. 13 y sig.

${ }^{7}$ Ver HARVEY, The condition of Postmodernity - An enquiry into the origins of Cultural Change, Cambridge, Massachusetts, 1994, p. 3 a 42; KAUFMANN Arthur, Grundprobleme der Rechtsphilosophie - Eine Rinführung in das rechtsphilosophische Denken, München, 1994, p. 224 y sig.

"JAYME Erik, Identité culturelle et intégration: Le droit internationale privé postmoderne - Cours général de droit international privé, 1995, in Recueil des Cours de 1

'Académie de Droit International de ka Haye, 1995, II, p. 36 y sig.

'JAYME, Recueil des Cours, ps. 247 y sig.

1i) Segun Gustavo Tepedino: "Com o termo multipropriedade designa-se, genericamente, a relaçâo juxidica de aproveramento econômico de uma coisa imóvel, repartida en unichades fixas de tempo, de modo que diversos titulares possam, cada qual a seu rurno, udilizar-se da coisa com exclusividade e de maneira perpétua", in TEPEDINO Gustavo, Multiptopriedade Imobiliária, Sarava, São Paulo, 1993, p.1. 
dificultades para la protección de esos mismos indivíduos ${ }^{11}$. Es un nuevo modelo contractual, cuyo estudio, asi como el de los varios tipos de multipropiedad ofrecidos en el mercado, gana cada vez más importancia y en consecuencia constituye la primera parte de este trabajo (I). El régimen de protección del consumidor en la formación y ejecución de los contratos de timesharing, bajo la óptica de la buena fe exigida en el mercado por el CDC brasileño, será el tema de la segunda parte de nuestro estudio (II).

\section{I - Time-Sharing como modelo de contrato postmoderno}

La constatación que nos lleva a querer estudiar los contratos de time-sharing sobre la óptica de la protección de los consumidores es el hecho que vivimos un momento de cambios, no solo legislativos sino políticos y sociales. Los europeos denominan este momento de rompimiento (Umbruch), de fin de una eta y de comienzo de algo nuevo, aún no identificado. Es la crisis de la era moderna y de sus ideales concretizados en la revolución francesa - libertad, igualdad, fraternidad - que no se realizaron para todos ni son hoy considerados como posibles, y cuya fuerza y suficiencia son relativas para servir de paradigma a la organización de las sociedades democráticas sumergidas actualmenre en un capitalismo neoliberal bastante agresivo, con efectos fuertemente perversos ${ }^{12}$. Vivimos un monento de alteración en el estilo de vida, de la acumulación de bienes materiales, del cambio de los contratos de dar para los contratos de hacer, de variación del modelo inmediatista de la compra y venta para un modelo duradero de la relación contractual, de la substitución, de la terceriarización y de las privatizaciones, de la transposición de relaciones meramente privadas para las relaciones particulares de inminente interés social o público ${ }^{13}$.

Realmente poco se sabe sobre este nuevo momento y poco son estudiados sus reflejos en el Derecho. El contrato de time-sharing fué escogido como paradigmático de estos nuevos tiempos ${ }^{14}$ y merece, en consecuencia, nuestro análisis más profundo.

A) Características postmodernas del contrato de multipropiedad.

\footnotetext{
${ }^{1 t}$ Así alerta KEMELMAYER DE CARLUCCI Aida, El tiempo compartido (mal liamada multipropiedad) y la defensa de los consumidores en el Derecho Comunitario Europeo. Posible proyección al Mercosur, in Derecho del Consumidor, vol. 7,1996, p. 92 y sig.

i2 Ver TOURRAINE Alain, Uma visão crícica da Modernidade, in Cadernos de sociología, vol. 5, p. 36 y 37.

${ }^{13}$ Así nuestra obrâ, Contratos no Código de Defesa do Consumidor, São Paulo: Ed. Revista dos Tribunais, 1995 , p. 60.

${ }^{14}$ Así TEPEDINO, p. 126; el autor observa en su conclusión que "A multipropriedade representa um marco sintonático e característico do processo de evolução e transformação do direito de propriedade, hoje concebido a través de noção múltipla, "instrumento de uma complexa e poliédrica função social"..."
} 


\section{La Cultura Postmoderna y el Derecho.}

De acuerdo con Erik Jayme las características de la cultura postnoderna en el Derecho serían: el pluralismo, la comunicación, la narracion, lo que el autor denomina "le retour des sentiments"y la valorización de los derechos humanos ${ }^{15}$.

Pluralismo de fuentes legislativas regulando el hecho, pluralismo de sujetos a proteger - algunas veces difusos como es el caso del grupo de consumidores o aquellos que se benefician de la protección del medio ambiente -, pluralidad de agentes activos como los proveedores que se organizan en cadena, en relaciones extremamente despersonalizadas ${ }^{16}$. Pluralismo en la filosofia aceptada donde el diálogo legitima el consenso, donde los valores son muchas veces antinómicos ${ }^{17}$.

La comunicación es un valor máximo de la postmodernidad asociado a la valorización extrema del tiempo, del Derecho como instrumento de comunicación, de la información como valorización del pasar del tiempo en las relaciones humanas, valorización de lo eterno y de lo transitorio, del congelar momentos y acciones pata garantizar la protección de los más débiles y de los grupos que la ley quiete privilegiar. La comunicación es el método de legitimación (Sprachspiele), la ética y la filosofía son discursivas, el consentimiento legitimante es únicamente aquel que sea informado y claro. Comunicación es igualmente internacionalidad de las relaciones juridicas y revalotización del derecho internacional privado así como de las técnicas de armonización y unificación de las leyes ${ }^{18}$.

La narración es la consecuencia de este impulso de comunicación, de la información que invade la filosofia del derecho y las propias normas legales. Habría un nuevo método de elaborar normas legales, no normas para reglamentar conductas sino normas que narran sus objetivos, sus principios, sus finalidades, positivando los objetivos del legislador en el micro-sistema de nanera a prestar auxilio en la interpretación teleológica y en el efecto útil de las normas ${ }^{19}$.

Lo quc Jayme denomina "le retour des sentiments" es, por un lado, la reaparición de una cierta "emocionalidad" en el discurso jurídico y, por el otro, lo imponderable, la búsqueda de nuevos elementos sociales, ideológicos $y / 0$ fuera del sistema que pasan a influir

\footnotetext{
${ }^{15}$ AYME, Recueil des Cours, p. 36.

16Ver sobre el pluralismo de fuentes FRIEDMAN Lawrence, The Republic of Choise - Law, Authority and Culture, Cambridge, Massachusetts, Harvard University Press, 1994, p. 11.

"Ver KAUFMANN, Grundprobleme, p. 226-227 y JAYME, Recueil des Cours, ps. 247 y sig.

"BVer igualmente SANCHEZ Lorenzo, p. 576 y sig.

"La definición de normas narrativas es de JAYME Erik, Narrative Normen im Internationalem Privat . und Vertahrensrecht, Mohr: Tübingen, 1993, p.16.
} 
la argumentación y las decisiones jurídicas creando inseguridad e imprevisibilidad en relación a la solución a ser encontrad $a^{20}$.

El último elemento destacado por Jayme es un revival de los derechos humanos como valores nuevos y únicos seguros a utilizar en este caos legislativo y desregulamentador de codificaciones y microsistemas, de leyes especiales privilegiadoras y de leyes generales ultrapasadas, de soft law y de búsqueda de una equidad cada vez más discursiva que real.

\section{La relación envolviendo el Time-Sharing como paradigma Postmoderno.}

Erik Jayme consideró el contrato de time-sharing, o multipropiedad, como el paradigma de contrato de la época postmoderna una vez que tal contrato posee una serie de características que pueden ser clasificadas como postmodernas comenzando por su objetivo que es el ocio temporario, o el uso de un inmueble y de sus servicios conexos en una área turística por una semana o dos cada año $0^{21}$.

Debe destacarse igualmente la naturaleza de los derechos asegurados a los consumidores. Derechos múltiples, aún cuando no todos de naturaleza real, ya que la multipropiedad en la mayoria de las veces no transfiere ni envuelve derechos de propiedad, únicamente derechos reales de uso. Estos derechos reales limitados de uso, aliados a una gran. cantidad de servicios anexos prestados, pueden permitir tipificar este contrato, preferencialmente, como un contrato de prestación de servicios ${ }^{22}$.

Otra característica importante es la multiplicidad de agentes que envuelve esa prestación de servicios y el goce de los derechos de uso asegurados por el contrato de timesharing, desde el organizador (el incorporador o verdadero proprietario del inmueble y del complejo turístico), el simple vendedor, el verdadero propietario, el administrador del inmueble y del complejo turístico, a los proveedores directos de la alimentación, de paseos, etc. Constituye muchas veces un contrato "sin fronteras" o internacional, pues las áreas y complejos turísticos muchas veces están localizados en otro país que el de domicilio o nacionalidad del consumidor, y la participación en "Cúrculos de intercambios internacionales"hace posible que el goce del derecho de uso temporario se dé en cualquier parte del planeta ${ }^{23}$.

\footnotetext{
${ }^{20}$ Asi, JAYME, Recueil des Cours, p. 261: "Ce qui frappe, c'est le recours, dans les arrêts des tribunaux, à la référence aux sentiments des personnes intéressés comme raisons poux résoudre des conlits de lois".

"Ver MARTINEK Michael, Moderne Vertragscypen, Tomo M, Munique: Beck, 1993, p. 268.

${ }^{22}$ En este sentido JAYME Erik, Europäisches Schuldvertragsübereinkommen, vergteichendes Übersetzen, Time-Sharing-Verträge, in IPRAX 1995, p. 135. Esta ciasificación como contrato envolviendo preponderantemente servicios es importante en Europa, una vez que la Untión Europea legisló sobre contratos de Tine-sharing en una Directiva especifica sobre el tema, debiendo señalarse que la Unión carece de comperencia para legislar sobre inmuebles y derecho de propiedad.

2"Asi, JAYMI, Recueil des Cours, p. 247 y sig.
} 
Resumiendo, es un contrato de múltiples servicios, de uso compartido de un inmueble, que puede envolver derechos de copropiedad, de participación en asociación com derecho a acciones, como si el contrato fuese de inversión, o com participación en emprendimiento hotelero. Un contrato cuya prestación se prolonga en el tiempo, se renueva y modifica com el pasar del tiempo y las múltiples posibilidades ofrecidas al consumidor, un contrato fluente, abierto, múltiple, creador de una dependencia entre el consumidor cautivo y los diferentes proveedores ${ }^{24}$.

Según Eril Jayme lo que caracteriza esencialmente el contrato de time-sharing como paradigmático de la era postmoderna son las propias expectativas múltiples de los consumidores-clientes al concluir tales contratos (double coding). No puede afirmarse que el time-sharing esté destinado únicamente a alcanzar y a usufruir directamente un periodo de vacaciones y un inmueble propio localizado en una área turística. Los contratos de timesharing son utilizados por los consumidores teniendo en cuenta el usufructo de sus vacaciones en un determinado local, pretendiendo asegurar que podrán cambiar el local de las mismas cuando así lo deseen, tornando un contrato nacional en un contrato con características internacionales $y$, finalmente, pudiendo utilizar tal contrato como un mero contrato de inversión sin que el consumidor pretenda jamás usufruir personalmente de los derechos asegurados por el contrato ${ }^{25}$.

En este sentido las legislaciones nacionales también presentan una serie de soluciones diferentes. La legislación portuguesa, pretendiendo favorecer las inversiones extranjeras en el país, protege al consumidor, a aquel que adquiere "derechos de uso habitacional" en Portugal2". En Grecia el contrato de time-sharing recibe un tégimen más proximo del artendamiento, mientras que en Francia la legislación lo aproxima del derecho de sociedades, forzando la organización de sociedades con síndicos y con una distribución clara de acciones y derechos de voto $^{27}$. Ya la legislación europea, la Directiva 94/47/CE de 26 de octubre de 1994 privilegia los servicios conexos al contrato de time-sharing y establece una protección positivada al contratante más débil ${ }^{28}$.

Recapitulando, los derechos asegurados a los consumidores en los diferentes tipos de contratos de time-sharing o multipropiedad pueden ser identificados de la siguiente manera: a) derechos de mero uso compartido del inmueble y de los diversos servicios; b) raramente derechos de copropiedad o propiedad parcial o compartida de un bien indivisible; c) derechos de participación en asociación o condominio conexos a derechos de uso de

\footnotetext{
${ }^{24}$ Así nuestra obra, Contratos no Código de Defesa do Consumidor, São Paulo: Ed, Revista dos Tribunais, 1995, p.127 y sig.

${ }^{25}$ JAYME, Recuei! des Cours, p. 247.

${ }^{26}$ Ver sobre o "direito real de habitação periódica"en el Derecho Portugués, TEIPEDINO, p. 35 y sig.

${ }^{27}$ Por mayores detalles consultar KEMELMAYER DE CARLUCCI, p. 101.

${ }^{28}$ Ver la exposición detallada de derecho comparado que hace JAYME, Recueil des Cours, ps. 247 y sig.; así como Schaaff, ps. 909 y sig.
} 
propiedad inmobiliaria de la asociación; d) derechos de intercambio de los derechos de uso y alquiler del inmueble que seria usado; e) derechos personales en cuanto a los servicios conexos al goce del espacio de ocio o de hoteleria que es objeto de algunos tipos de timesharing.

En consecuencia el time-sharing es en esencia una telación contractual destinada a la adquisición de un derecho de habitación temporaria o compartida que puede envolver derechos de uso pero que no siempre encierra la propiedad o la multipropiedad, como parece querer afirmar su propio nombre en francés (multipropriété), en italiano (multiproprietà) y en español (multipropiedad) ${ }^{29}$.

\section{El Time-Sharing como desafío para la ciencia actual del Derecho: un contrato cautivo de larga duración y fluente}

La protección del consumidor en contratos comprendiendo preponderantemente servicios constituye un nuevo desafio para la ciencia del Derecho Civil. La complejidad existente en los contratos de time-sharing y la poca comprehensión que el consumidor tiene de sus deberes y derechos futuros (teniendo en cuenta que la mayoria de las personas piensa estar alcanzando, a través de estos contratos, la copropiedad de inmuebles en áreas turísticas, lo que no siempre es verdadi) ${ }^{30}$, demuestran la necesidad de una protección mayor del consumidor al contratar así como durante la ejecución de tales contratos, ya que estos pueden vincular los consumidores de manera perpetua ${ }^{31}$ o hasta por ochenta años, como lo permite la ley francesa ${ }^{32}$.

En nuestra obra sobre contratos denominamos estos nuevos contratos complejos "contratos cautivos de larga duración" de manera a no necesitar utilizar la expresión europea de contratos postmodernos. Nuestra intencion era resaltar que una serie de nuevos contratos hoy ofrecidos en el mercado lationamericano son contratos de masa, impersonalizados, concluidos con la técnica de los contratos de adhesión y/o condiciones generales de los contratos, envolviendo una cadena organizada de proveedores que permanece desconocida o menospreciada por el consumidor pero que acaba por colocarlo en una condición acentuada de dependencia y cautividad en el momento en que la prestación es exigible. El consumidor es cliente cautivo de una empresa pero ésta no le proveerá directamente los servicios, ni se responsabilizará por la calidad de los servicios prestados. El consumidor se relaciona

\footnotetext{
${ }^{29}$ Ver por todos TEPEDINO, p. 1.

${ }^{33}$ En este sentido, KEMELMAYER DE CARLUCCI, ps. 98 y sig,

"Según TEPEDINO en la multipropiedad (inmobiliaria) el derechos "pode ser perpétuo quanto à duração, embora temporário quanto ao seu exercício...). TEPEDINO, p. 1 y 5.

${ }^{32}$ Ver las leyes francesas, Loi n. 65-557 de 10 de julio de 1965 sobre copropiedad y la Loi n. $86-18$ de 6 de enero de 1986 sobre goce a tiempo compartido. Ver tambiéra las críticas de KEMELMAYER DE CARLUCCI, ps. 101 y sig.
} 
personalmente con el proveedor directo pero contrata con el proveedor indirecto, creador y organizador de la cadena de servicios. Son relaciones triangulares, con múltiples agentes que tornan aún más vulnerable e insegura la posición del consurnidor y de su familia, que gozan del servicio.

Los problemas más comunes detectados en los contratos de time-sharing han sido: el conocimiento por parte del consumidor de los derechos que está realmente adquiriendo $o^{33}$ y de las reglas de uso del inmueble ${ }^{34}$; la situación del consumidor en caso de que el proveedor/incorporador no concluya la obra, no entregue los inmuebles para uso de los consumidores o sea declarado en estado de insolvencia o quiebra; la transmisiblidad del time-sharing y su inclusión entre los derechos hereditarios; los vicios, fallas o problemas en los servicios prestados por los complejos turísticos, por los complejos de vacaciones y viajes ${ }^{35}$; la variabilidad y abuso en las tasas de administración y las cláusulas de perdida de las cuantías pagadas y carencias de los más diversos tipos ${ }^{36}$.

Analisemos entonces los tipos de contratos de multipropiedad o time-sharing y la naturaleza de los servicios $\mathrm{y} / \mathrm{o}$ derechos reales colocados a disposición de los consumidores en el mercado.

\section{B) Tipos de Time-Sharing}

La fórmula del time-sharing nació en Francia pero fué en los Estados Unidos de América que conoció, en los años 70 y 80 , su gran desarrollo, conquistando al final de los años 80 Europa y en los años 90 América Latina. El éxito de la fómula se debe a su pragmatismo y flexibilidad: resuelve la crisis del sector hotelero y turistico-inmobiliario al asegurarle consumidores cautivos, exigiendo en cambio una pequeña inversión de los clientes ávidos de alcanzar el tan esperado ocio y descanso en áreas turísticas valorizadas ${ }^{37}$.

Por una pequeña suma de dinero el consumidor y su familia alcanzan el goce de un espacio, de un inmueble, en una localidad turística de gran demanda sin tener que soportar los costos normales de un inmueble propio (mantenimiento continuo, impuestos, etc.) todo esto combinado con ventajas organizacionales: posibilidad de alquilar para otros su

\footnotetext{
${ }^{33}$ AsI TEPEDINO, p. 49.

${ }^{34} \mathrm{E}$ n este sentido la jurisprudencia ha permitido reabrir el periodo de arrepentimiento del art. 49 del CDC de 7 dias después de la comunicación y conocimiento de las ciáusulas y previsiones sobre la forma en que se dará efectivamente el uso del inmueble. Ver sentencia de 10 de septiembre de 1996, 9 Cámara Rel. Marin Isabel de Azevedo Souza, TARGS.

${ }^{35}$ Ver por todos TEPEDINO, p. 122.

${ }^{36}$ Asi MARTINEK, ps. 281 y sig.

${ }^{34}$ Asi ARRIVAS Fabio, La multiproprietà in Contratu in Generale, Guido Alpa (Coord.), Uutet, Milán, 1994, p. 1133 y TEPEDINO, p. 2.
} 
"semana de vacaciones" o aún, en caso de no usufructuar en su tiempo y lugar determinado, de cambiar sus "derechos habitacionales de uso" de manera a gozar sus vacaciones en otro lugar del mundo a través de una bolsa internacional de intercambios ${ }^{38}$. Su éxito se debe también al momento postnoderno de la búsqueda del ocio, de lo internacional, de la seguridad de un momento especial de vacaciones, del deseo de los turistas de tener, por lo menos por algunas semanas pot año, una "casa de vacaciones" propia. Es, en las palabras de Jayme, un contrato envolviendo sentimientos nostágicos ${ }^{39}$. Un contrato múltiple, fluente, complejo y con varias subespecies que serán presentadas rápidamente a continuación.

\section{Multipropiedad Hotelera}

La multipropiedad hoteleta o time-sharing hotelero está caracterizada por el hecho de que la unidad inmobiliaria sobre la cual se atribuye el derecho de uso habitacional temporatio está incluída en un complejo hotelero (red de hoteles, complejo turístico con hoteles de varias categorías o un hotel aislado que trabaje con contratos de time-sharing $)^{40}$. Este complejo hotelero pertenece bien a un propietario único, proveedor de servicios de hotelería y que asegura a los consumidores de time-shating apenas derechos de uso habitacional por determinado lapso de tiempo, bien a una sociedad administradora propietaria, en la cual tendrá participación el consumidor, o bien los propietarios son muchos, todos los consumidores de time-sharing junto con el incorporador, organizador a hotelero, que participan de una comunión de división de propiedades o multipropietarios ${ }^{41}$.

En este tipo de time-sharing el consumidor recibe un bono o cuota de acuerdo con el cual podrá, por cierto periodo de tiempo, usar un apartamento de determinada clase en el hotel y recibir determinados servicios del mismo (desayuno, cambio y lavaje de ropas de cama, campos de deporte y de placer, viajes organizadas, etc.), pudiendo también ceder sus derechos a terceros, por lo que recibirá determinada cuantía a su favor ${ }^{42}$.

Según Arrivas es este el tipo de time-sharing donde las relaciones entre el proveedor y el consumidor se encuentran en equilibrio, pues el consumidor se interesa en recibir los servicios de un hotel y no tanto en recibir el dominio, aun cuando temporario, del inmueble en el área turística. El mantenimiento de los apartamentos del hotel son igualmente más fáciles por la impersonalidad y los costos mejor divididos, así como por la posibilidad de alquilar para terceros las semanas no utilizadas por el consumidor. Se trata de un verdadero derecho de crédito-hotelero de días de vacaciones en un complejo hotelero, con ventajas

\footnotetext{
${ }^{34}$ SCHAAFF Petra, Time Sharing - Modell oder Risiko?, in ZIP 1984/8, ps. 908 y sig.

${ }^{39}$ JAYME, Recueil des Cours, p. 247.

4heguimos aquí la denomiración utilizada por ARRIVAS, p. 1135.

${ }^{41}$ Así también TLPEDINO, p. 18.

${ }^{42}$ Ver MARTINEK, p. 282 y ARRTVAS, p. 1135.
} 
extras de intercambio eventual y de utilización de toda la red mundial de hoteles ${ }^{43}$.

El problema de este modelo de time-sharing fué detectado en Italia por el Estado que llegó inclusive a combatirlo, pues el vínculo hotelero y la seguridad de los terceros que utilizan los hoteles pasa de la mano de un solo propietario hotelero para las manos de una centena de copropietarios de time-sharing, bajando el nivel de los servicios de hotelería, cambiando la destinación del inmueble y violando los subsidios concedidos al sector hotelero ${ }^{\text {th }}$. Efectivamente, aquí es necesario un mayor control del Estado y posiblemente la elaboración de una legislación administrativa y urbanística específica para estos complejos hoteleros.

El segundo problema presentado por este tipo de time-sharing en el Brasil fué el peligro, común a todos los contratos, de que el proveedor o incorporador no pueda construir el emprendimiento hotelero pretendido, a pesar de haber recaudado el ahorto de los consumidores. En este caso el Tribunal de Alçada de Rio Grande do Sul permitió la resolución del contrato y decretó la devolución de las cuantías pagadas, debido a la insolvencia cél hotelero-emprendedor y del peligro inminente de no conclujel inmueble prometido ${ }^{45}$. A la mora del proveedor se contrapuso el derecho extintivo del consumidor y el factor tiempo fué destacado como característico del time-sharing, declarando el Tribunal: "Nesses empreendimentos, seja porque visassen o lazer pessual do interessado, seja porque objetivassen investimento, o tempo é fator considerável, sendo demasiado o já ocorrido entre a data de conclusão prometida (1990) e a de hoje (1994$1997) . "$ "⿻

\section{Multipropiedad inmobiliaria o de complejo de placer.}

La multipropiedad inmobiliaria es el modelo de tirne-sharing que conquistó en Europa nayor éxito, probablemente por su proximidad con el concepto clásico de propiedad. Esta proximidad es, sin embargo, motivo de fuertes críticas si se toma en consideración la limitación, el numerus clausus, que los paises de la familia continental europea, los ordenamientos juridicos de origen romano-gemánica, conocen de los derechos reales.

\footnotetext{
${ }^{43}$ ARRIVAS, p. 1135.

${ }^{4}$ Ver detalles en TEPIEDINO, p. 20.

45entencia de 15 de marzo de 1995, 7 Cámata TARGS, Rel. Antonio Janyi Dall'Agnoll Júnior, Proceso n. 194255485: PROMESSA DE COMPRA E VENDA. RESOLUÇÃO MORA NA CONCLUSÃO DE OBRA. PERDAS E DANOS. ..."Procede a resoluçäo de promessa de compra e venda, proposta pelo promitente comprador quando a mora na conclusão da obra alcança extensão que vem inutilizando a finalidade ordinaria para a qual previsto o empreendimento. Assim, a indefinição quanto a conclusão de prédio hoteleiro em sistema de tempo repattido (time-sharing), pelo promitente vendedor, em detrimento manifesto do promitent

e comprador, que cumpre, atıalizadamente, com parcelas de sua prestação. Perdas e danos que se afastam, respeitantes ao interesse positivo, por ñ̃o satisfatoriamente demonstradas e insuficientemente registradas na inicial. Apelo parcialmente provido.".

"Sentencia de 15 de marzo de 1995, 7 Cámara TARGS, Rel. Antonio Janyr Dall'Agnoll júnior, Proceso $n$. 194255485, p. 7 del original.
} 
En este contrato el consumidor adquiere una cuota en un complejo inmobiliario, cuota que se extiende a parte del suelo edificado, al terreno, al complejo de ocio común, a los muebles existentes en el complejo y a todo lo que torne posible el goce del bien inmueble. Se conjugan un régimen de comunión, que disciplina la modalidad de uso de la unidad habitacional, la destinación residencial fija y un régimen de indivisibilidad perpétua de "semipropiedad" transferida y un régimen de condominio, condominio que reglamenta el uso de las partes comunes y los critérios de repartición de los bienes comunes, así como la adquisición de estos. La característica especifica de este tipo de time-sharing es que la concesión de un derecho de uso o el derecho de goce, aun cuando reales, sea limitado en el tiempo a un periodo de algunas semanas en el año, a pesar que el derecho cedido en sí tenga larga duración, pudiendo inclusive llegar a ser perpétuo ${ }^{47}$.

El problema de clasificación de este tipo de multipropiedad es grande pues se trata de una forma mixta en que se aseguran derechos reales con cierta limitación temporatia de su ejercicio y derechos personales de mayor importancia en la relación contractual, al mismo tiempo que es imposible clasificar la propiedad eventualmente concedida a los consumidores como propiedad temporaria, propiedad pasible de resolución o cualquier otra especie de derecho real tipificado ${ }^{48}$. Es un novum y en este sentido un riesgo extra para los consumidores ${ }^{4)}$.

\section{Multipropiedad accionaria}

Esta subespecie de contratos de time-sharing tuvo mucho éxito en los Estados Unidos y en Francia, donde fué reglamentado por las leyes de 28 de julio de 1938 y de 16 de julio de $1971^{\text {st }}$. El modelo de multipropiedad consiste substancialmente en la constitución de una sociedad, propietaria del inmueble, que emite acciones ordinarias y acciones preferenciales que serán vendidas. Las acciones ordinarias rcpresentan la propiedad del inmueble y quedan en poder de los cfectivos propietarios del complejo inmobiliario y de placer, ya que permiten a los socios participar de la gestión social. Las acciones preferenciales, a las cuales les

\footnotetext{
${ }^{47}$ Ver MARTTNEK, p. 277; ARRIVAS, p. 1139 y 1140 ; TEPEDINO, ps. 15 y sig. ${ }^{48}$ ARIRIVAS, P. 1141.

${ }^{49} Y$ Tepedino observa en este modelo una mayor seguridad para los adquirentes y busca aplicar las normas brasileñas sobre condominio e incorporaciones a esta relación de time-sharing inmobiliario, ver TEPEDINO, ps. $16 \mathrm{y}$ sig, $110 \mathrm{y}$ sig.

${ }^{5} \mathrm{MARTINEK}$, p. 278
} 
es atribuido el derecho de voto en las asambleas, son vendidas a los usuatios y consumidores del time-shating y conceden a estos el derecho de utilización del bien compartido en turnos ${ }^{54}$.

El promotor de la iniciativa o incorporador contrata con los consumidores y distribuye las acciones preferenciales y, en la mayor parte de los casos, se compromete a entregar las acciones ordinarias a los copropietarios, una vez saldada completamente la deuda, en la proporción de su participación en la propiedad del inmueble, o se compromete a administrar el complejo inmobiliario, constituyendo otra sociedad y dando voz activa en ella a los propietarios de las acciones. Estos dos submodelos no evitan los riesgos que conlleva el trabajar en el mercado de acciones y traen para el time-sharing un carácter de contrato de inversión apartandose de su naturaleza de simple contrato múltiple de servicios y de uso habitacional para el ocio. El vínculo del time-sharing accionario con su finalidad primera, de espacio inmobiliario para el ocio en una área turística, queda más tenue y puede simplemente desaparecer ${ }^{52}$.

\section{Contratos nacionales e internacionales de time-sharing.}

Los contratos de time-sharing presentan varios elementos de extranjería y muchas veces pueden ser considerados contratos internacionales, lo que dificulta aún más una efectiva protección de los consumidores en este tipo contractual ${ }^{53}$. Muchas veces los inmuebles, los complejos hoteleros o de placer, cuyo goce es ofrecido a través de contratos de multipropiedad se localizan en áreas de turismo fuera del territorio de domicilio o de nacionalidad del consunidor. Así, en el territorio brasileño son ofrecidas, mediante campañas agresivas de marketing y ventas, contratos de time-shating que aseguran la utilización de inmuebles localizados en Punta del Este, Uruguay, o en la Argentina, en cuanto son ofrecidos para consumidores argentinos contratos de multipropiedad envolviendo el uso de inmuebles localizados en las playas brasileñas.

Los sujetos vinculados también pueden ser extranjeros, como en el caso de un timesharing vendido en Porto Alegte, Brasil, por un incorporador en nombre de una sociedad propietaria y administradora argentina, de un complejo de ocio localizado en Uruguay. Los propios contratos se encuentran redactados en español y con la traducción en portugués.

Si eventualemente los inmuebles iniciales se localizan en el país de domicilio de los consumidores y los agentes proveedores son todos personas jurídicas con sede en este mismo país, la posibilidad de integrar un circulo de intercambio puede resultar en el goce de

\footnotetext{
${ }^{51}$ TEPPEDINO, p. 9; SCHAAFF, p. 911 y ARRIVAS, p. 1138.

${ }^{52}$ Ver crítica de ARRTVAS, p. 1138 y 1139.

${ }^{53}$ Así también menciona el "caxáctex txansfronterizo del time-sharing" KEMELMAYER DE CARLUCCI, ps. 100 .
} 
vacaciones en el exterior con envolvimiento de proveedores extranjeros. El time-sharing fué definido por Erik Jayme como un contrato "sin fronteras" lo que bien denomina su tendencia internacional.

La jurisprudencia brasileña ha considerado la internacionalidad del contrato como un peligro extra para el consumidor y ha asegurado la reapertura del plazo de reflexión de 7 días del CDC cuando el consumidor brasileño es informado en portugués del tenor del negocio, en especial de las cláusulas limitadoras de sus derechos y de aquellas que apartan derechos reales de propiedad, a pesar de que el contrato pueda insinuar la adquisición de esos derechos ${ }^{54}$. En este caso la jurisprudencia destaca la importancia de los principios debuena fe y de la protección de la confranza del consumidor, una vez que la publicidad y la venta tienen lugar en territorio brasileño; constituye su extensión la teoría de la apariencia para establecer la responsabilidad solidaria y la legitimación pasiva de todos los diversos proveedores (directos y representantes) relacionados en la negociación ${ }^{55}$.

\section{II - Protección del consumidor en la formación y ejecución de los contratos de time-sharing}

La ley 8.078/90, generalmente denominada Código de Defensa del Consumidor, es aplicable a todas las telaciones de consumo contractuales y extracontractuales en el mercado brasileño, o sea a aquellas que tengan como partes un consumidor y un proveedor de servicios o de productos. El CDC brasileño prefirió una denominación amplia de consumidor ${ }^{56}$. Consumidor es el destinatario final de productos y servicios ("consumidor. stricto sensu" según el art. 2, caput del CDC), también toda la comunidad afectada por las prácticas abusivas en materia de consumo (por ejemplo por publicidad engañosa o abusiva,

\footnotetext{
${ }^{54}$ Ver sentencia de 19 de diciembre de 1996, 9 Cámata Rel. Maria Isabel de Azevedo Souza, TARGS, proceso n. 196182760: "MULTIPROPRIEDADE. Contrato internacional. Contratação no Brasil. Empreendimento localizado no Uruguai. Lingua estrangeira. Promitente vendedor. Mandatário. Teoria da aparência. Desconhecimento das cláusulas relativas ao uso do imóvel Art. 49 do CDC.

1. É parte legitima para figurar no polo passivo da ação de resolução de contrato internacional de promessa de compra e venda de açóes relatira ao uso de imóvel pelo sistema de multipropriedade a empressa bralieira que, no Btasil, promove a informação, publicidade e oferta do empreendimento a ser realizado no exterior como se fosse titular do direito. A transmissão de confança de uma situação jurídica e a omissäo de sua real condição de mandatária importa na sua responsabilictade pela contratação. Ainda mais quando foi a responsável pela elaboração do contrato tendo infringido o princípio da transparência e do dever de informáção. Fere o princípio da boáfé e da doutrina dos atos próprios a alegaçăo de iletimidade passiva "ad causam".

"Sentencia de 19 de diciembre de 1996, 9 Cámara Rel. Maria Isabel de Azevedo Souza, TARGS, proceso n. 196182760 , ps. 6 a 8, citando las lecciones de Luiz. Diez. Picazo y de Gustavo Tepedino.

St Ver los comentarios de BENJAMTN Antônio H.V., Art. 17 del CDC, in; Comentários al Código de Proteção do Consumidor, Juarez de Oliverra (Coord.), Saraiva, Sào Paulo, 1991, p. 80.
} 
por la imposición de cláusulas abusivas, etc.) e igualmente las victimas de los daños provocados por productos o servicios defectuosos ("personas equiparadas a consumidores"según el art. 2, §único, art. 17 y art. 29 del CDC). El CDC brasileño no hace distinción entre consumidor e usuario, incluyendo a todos en la definición de consumidor. El proveedor es un profesional, persona fisica o jurídica, nacional o extranjera, que vende, produce, fabsica, comercializa un producto u ofrece un servicio en el mercado de consumo brasileño (art. 3 del CDC). El proveedor puede ser igualmente un profesional liberal, un profesional especializado como los bancos o las instituciones financieras y de concesión de crédito y aún las aseguradoras (art. 3, 72 del $C D C)^{57}$.

El CDC es aplicable tanto a los contratos de adhesión como a los contratos paritarios o individuales discutidos cláusula a cláusula, siempre que constituyan contratos de consumo, una vez que el legislador brasileño no quiso limitar la protección contractual contráa las cláusulas abusivas solamente a aquellos que utilizasen de los métodos de contratación en masa ${ }^{58}$. Las normas impuestas por el CDC son de orden público (ex vi art. 1 del CDC), destinadas a proteger los consumidores individuales, pudiendo también ser invocadas por las asociaciones de defensa de los consumicores, por el Ministerio Público y los demás legitimados para las acciones civiles públicas (art. 80 y art. 100 del CDC).

Gracias a la definición amplia de su campo de aplicación la doctrina mayoritaria actual considera que el CDC se aplica a los contratos de time-sharing o multipropiedad. Las relaciones de consumo que envuelven directa o indirectamente la prestación de servicios de placer, de hoteleria, de uso compartido de inmuebles, de arrendamiento inmobiliatio y de multipropiedad se someten en general al régimen del Código Brasileño de Defensa del Consumidor (a.t. 3 del $\mathrm{CDC}$ ).

El Código de Defensa del Consumidor impone para las relaciones comprendiendo prestación de servicios onerosos en el mercado y el aprovisionamiento de productos un nivel mínimo debuena fe objetiva en tales contratos y relaciones de consumo (art. 4, inciso II del $(\mathrm{CDC})^{59}$. La función positiva de la buena fe se refleja en la creación e imposición de nuevos deberes al proveedor de servicios o productos en el mercado brasileño, como los deberes de información, cooperación y cuidado, así como una nueva noción de gatantía esencial a la

\footnotetext{
${ }^{57}$ La definición amplia de "proveedor" de productos y servicios es catacterística del derecho brasileño, ver MUKAI Toshio, in: Comentários al Código de Proteçầo do Consumidor, Juarez de Oliveira (Coorà.), Saraiva, São Paulo, 1991 , p. 8.

58 Asi GRINOVER A P., Código Brasileiro de Defesa do Consumictor, Comentado pelos autores do Anteprojeto, Forense, Rio de Janeiro, 1991, p. 22.

50 Sobre la buena fe en las reglas de consumo y la cláusula general de buena fe del art. 51, inciso IV del CDC ver AGUIAR Jr. Ruy Rosado de, A boa-fé na relação de consumo, in Direito do Consumidor, vol. 1.4 , ps. 20 y sig.
} 
prestación y de vicio del servicio. La función negativa de la buena fe se refleja en la limitación de la libertad de establecer libremente el contenido del contrato a través de la imposición de un nuevo nivel de conducta no abusiva de aquel que establece efectivamente las cláusulas contractuales.

A) Formación del contrato de time-sharing de acuerdo con la buena fe.

En realidad, el Código de Defensa del Consumidor positivó en el Derecho Civil brasileño la cláusula general de buena fe, una buena fe objetiva ya conocida como principio implicito en el Código Civil de 1916. Buena fe significa un pensar con reflexión, un nivel mínimo y objetivo de cuidados, de respeto y de tratamiento leal con la persona com quien se realiza el contrato y con sus dependientes ${ }^{60}$. Este nivel de lealtad, cooperación, información y cuidados con el patrimonio y la persona del consumidor está impuesto por la norma legal, teniendo en cuenta la aversión del derecho al abuso y a los actos abusivos practicados por el contratante más fuerte, el proveedor, con base en la libertad asegurada por el principio de la autonomia privada. El CDC presume el consumidor como parte contractual más vulnerable por ley (art 4, inciso I del CDC) e impone a los proveedores de servicios en el mercado brasileño un nivel mínimo de actuación conforme a la buoná fe.

El principio de la buena fe en las relaciones de consumo actua limitando el principio de la autonomía de la voluntad (art. 170 caput e inciso V de la Constitución Federal de 1988) y combatiendo los abusos practicados en el mercado.

La imposición del principio de la buena fe y de la confianza como Leitline de las relaciones de consumo en el mercado brasileño contempla en sí una visión más amplia de la relación contractual, que valoriza el periodo pre-contractual, el periodo de aproximación negocial entre el proveedor, com sus métodos de venta y de marketing, y el grupo aún incierto de consumidores en potencial expuestos a los métodos genéricos de marketing de los proveedores. La relación contractual de consumo pasa a ser vista como un proceso dinámico, a unir durante cierto tiempo en contactos reiterados un consumidor y un proveedor ${ }^{6 !}$. Esta visión modifica la noción de abusivas de las cláusulas contractuales. Igualmente aclara que el desequilibrio de derechos y deberes en el contrato se refleja en prácticas contrarias a los deberes de conducta de acuerdo con la buena fe, violando así de manera oblicua, indirecta, las expectativas (ahora) legítimas del consumidor.

\footnotetext{
(1) Sobre la buena fe como regla (objetiva) de conducta en las relaciones contractuales y en el CDC ver JUNQUERA DE AZEVEDO Antonio, A boa-fé na formação dos contratos, Direito do Consumidor, vol. 3 , ps. 78 y sig.

6) Ver LARENZ Karl, Schuldrecht I, Munique: Beck, 1987, ps. 26 y sig.
} 


\section{Protección de la voluntad reflexiva y racional del consumidor}

En el derecho comparado se observa que las técnicas legislativas de protección a los consumidores en materia de contratos de time-sharing están destinadas inicialmente a garantizar una nueva protección de la voluntad de los consumictores, o sea a garantizar una autonomía real de la voluntad del contratante más débil. Una voluntad protegida por el derecho, voluntad libre de las presiones y de los deseos impuestos por la publicidad y por otros métodos agresivos de venta, como las invitaciones para fiestas y reuniones donde se distribuyen bebidas alcoholicas, las visitas organizadas y gratuitas a los locales de ocio, la oferta de juegos y premios, las visitas, las llamadas telefónicas y los contactos reiterados para hacer presión. La decisión carente de reflexión, no preparada, emocional del consumidor está vinculada fácticamente a una serie de peligros, vale la pena recordar los fenómenos actuales del super-endeudamiento, de la insolvencia, de los abusos contractuales, de la frustración de las expectativas legitimas, etc. Las ventas de time-sharing generalmente ocurren a través de métodos agresivos de marketing y cuentan com la decisión no pensada y emocional del consumidor.

\section{a. Voluntad racional versus voluntad emocional}

Esta "nueva autonomía" reflexiva y calificada de la voluntad del consumidor fué denominada por Nicole Charbin, en su tesis de doctorado de 1988 de voluntad racional ("volonté rationnelle") ${ }^{62}$. Como ya tuve oportunidad de afirmar, esta denominación me parece bastante acertada pues indica la importancia de los nuevos derechos de los consumidores, el derecho a la información, el derecho a la reflexión y al arrepentimiento incondicional en contratos envolviendo crédito al consumidor, caso analisado especificamente en la tesis de Nicole Chabrin. La Directiva Europea 94/97/CE de 26 de octubre de 1994 pretende asegurar la voluntad racional y reflexiva del consumidor a través de tres instrumentos: a) en su anexo trae una lista detallada de las informaciones y aclaraciones que el contrato o pre-contrato debe contener y en una lengua conocida por el consumidor; b) en su art. 5-I, prevee un derecho de arrepentimiento inmotivado de 10 dias a partir de la firma del contrato o pre-contrato; c) en su art. 5-I, prevee igualmente un derecho de arrepentimiento por tres meses, caso alguna de las informaciones previstas en el anexo no conste en el contrato o precontrato o no haya sido convenientemente informada al consumidor. Caso el proveedor informe al consumidor lo que faltaba en su precontrato o contrato, la entrega de estas informaciones reabre el plazo de arrepentimiento de 10 días, antes mencionado. El artículo 5 de la Directiva rambién prohibe el pagamento antes del décino día y exige la traducción del instrumento contractual en alguna lengua conocida por el consumidor ${ }^{63}$.

62 CHABRIN Nicole, Le contrat de consommation de crédit et l'autonomie de la volonté, LGDJ, Paris, 1988, Bibliothèque de Droit Privé, Tome CXCIX, p. 216.

${ }^{63}$ Amtsblatt de EG, I. 280/85. 
Aún en una perspectiva de derecho comparado, se observa que las leyes protectoras del consumidor persiguen un segundo objetivo, en lo que respecta la protección de la voluntad del consunidor, cual es el de asegurar a este ciertos derechos por ley a los cuales no puede renunciar ${ }^{64}$, o estableciendo de manera imperativa la prohibición de ciertas cláusulas consideradas abusivas en los contratos de consumo ${ }^{65}$. Los contratos de time-sharing son generalmente contratos de adhesión, redactados unilateralmente por los profesionales, por lo cual ciertos cuidados en la redacción son necesarios. Esta nueva función de las normas protectoras de los consumidores puede ser caracterizada como función negativa ya que ella reduce, limita, la libertad de quien elabora el contrato. Limita la libertad contractual (ver los arts. 39 y 51 del CDC) pues prohíbe la transferencia de ciertos riesgos para los consumidores (ver la lista de cláusulas abusivas del art. 51 del CDC).

Efectivamente el CDC se destina también a ese primer objetivo, o sea el de asegurar al consumidor una decisión fundada en el conocimiento de todos los elementos del contrato, en particular del precio, de las tasas extras, de las condiciones y de las garantías exigidas, de las cláusulas limitativas y penales incluídas, de los verdaderos derechos asegurados por el contrato. Es en esta óptica que el art. 46 del CDC prevee la posibilidad de solicitar al juez, en detrimento del proveedor, la liberación del consumidor del vínculo contractual, o sea, la inoponibilidad del contrato al consumidor si no le fuere dada la oportunidad de tomar previo conocimiento del contenido contractual antes de la firma de este ${ }^{6.6}$. El conocimiento previo del texto del contrato y de las obligaciones en él contenidas, en portugués, es considerado condición esencial para la formación de una voluntad tealmente libre, consciente, "racional".

\footnotetext{
S4 Ver nuestro articulo sobre contratos de crédizo, Os contratos de crédito e a legislação buasileira de proteçào do consumidor, in Revista Direito do Consumidor, vol. 17, ps. 35 y sigg; igualmente consultar f'HEUREUX Nicole, Précis de Droit Commercial, Presses de l'Université Laval, Quebec, 1975, p. 226 "nis Asi CALAS-AULOY J, Les cing réformes qui rendrajent le crédit moins dangereux pour les consommateurs, in Recueil Dalloz, 1975, Chron., p. 21.

th Este artículo 46 há sido ampliamente utilizado por la jurisprudencia brasilena, aún por los Yuzgados Especiales de Pequeñas Causas. Ver decisión de la 1a Turma Recursal dos Juizados, Recurso n.01196885485, proc. 01196611964 de Porto Alegre, Rel. Juez de Derecho Wilson Carlos Rodicz: "TIMIB-SHARING TEMPO COMPARTILHADO. NULIDADE DAS CLAUSULAS ABUSIVAS. VALOR DA CAUSA E COMPETENCIA DOS JUTZADOS/JEC; 1. O valor da causa, nesse tipo de pedido, corresponde ao bem da vida reivindicado - no caso o valor das pres

tações é objeto do pedido de restituição. 2. Nulidade das cláusulas que colocam o consumidor em desvantagem exagerada (CDC 54, IV); possibilidade de denúncia do contrato a qualquer tempo em razão do vício de manifestaçào da vontade, captada em circunstâncias em que o descortinio crítico estava prejudicado pela atmostera criada pela vendedora (CDC, 46). Recurso desprovido.".
} 
b. Combate a la contratación emocional y el derecho de arrepentimiento

La ley brasileña de 1990 no prevee expresamente una norma sobre el plazo de reflexión en caso de contratos de multipropiedad, apenas el artículo general sobre el derecho de reflexión de 7 días asegurado por el art. $49 \mathrm{CDC}$. En la venta emocional del time-shating el consumidor no reflexiona su decisión, se obliga contractualmente de manera inmediata y llena boletos de cartas de crédito que txás tarde lo comprometerán para el futuro y que lo obligan a direccionat su ocio de manera muchas veces indeseada y por periodos que pueden ser hasta de 300 aún 80 años!.

La experiencia demostró que en materia de contratos de time-sharing, por el propio poder de seducción de la idea de asegurar ocio y descanso en los días de hoy, aún en casos de contratos formalizados y conclúdos dentro de los establecimientos comerciales, el consumidor tiene necesidad de un plazo extra para pensar detalladamente. Como lo afirma Alberto do Amaral Júnior, asegurar unicamente la información correcta es insuficiente para garantizar la protección del consumidor si no se le deja un tiempo necesario para la formación libre y clara de su voluntad ${ }^{\text {a? }}$. El tiempo, aliado a la información es eficiente, no la información en estratégias directas y agresivas de venta que unicamente aumentan el desequilibrio y la presión en las negociaciones contractuales. Esta reflexión puede evitar el super-endeudamiento, evitar que se asuman obligaciones indeseadas, así como la insolvencia en vínculos no examinados ni deseados. El tiempo y la información son los nuevos instrumentos en tiempos postmodemos para combatir la tan relevante "presión" en los métodos agresivos y emocionales de venta ${ }^{6 \%}$.

La ley brasileña prevee un derecho de reflexión y de arrepentimiento unicamente en el caso de contratos conclúdos fuera del establecimiento comercial (art. $49 \mathrm{CDC}$ ), por ejemplo en el caso de la venta a domicilio o por teléfono etc. En Brasil, si de un lado podemos deducir la intención del legislador del CDC de proteger la "voluntad racional"en los contratos fuera del establecimiento comercial, es necesario interpretar esta norma del art. 49 del CDC de forma abierta para poder incluir los más variados métodos de conrratación emocional en materia de time-sharing, así como el marketing directo. Muchos de estos métodos agresivos de convencimiento y estratégias de venta son ejecutados dentro del "pretendido" o aparente establecimiento comercial del organizador de ventas o del proyecto de placer, en fiestas, en reuniones y com distribuciones de pretendidos premios granitos. Así há decidido sabiamente la jurisprudencia brasileña:

\footnotetext{
67 AMARAL Jr. Alberto do, Comentários no Código de Proteçăo do Consumidor, Saraiva, São Pavio, 1991, p. 188.

${ }^{67}$ Asi lo afuma la decisión de la la Turma Recursal dos Juizados, Recurso n.01196885485, proc. 01196611964 de Porto Alegre, Rel. Juez de Derecho Wilson Carlos Rodicz: "No mérito, não há dúvida de que a captação da vontade do adquirente encontra-se viciada. O método de venda excessivamente agressivo praticado pela té comporta as acusações feitas na inicial de que foi vítima de pressão psicológica para aderir a um empreendimerito sem possibilidade de reflexão."(p. 1).
} 
"CONTRATO PARTICULAR DE PROMESSA DE COMPRA E VENDA de Fração ideal $1 / 52$ de unidade a ser construída em condominio. Utilização por períodos anuais. Tempo compartillado. Cláusulas abusivas. Decretação de nulidade de oficio. Direito de Arrependimento. Código de Defesa do Consumidor. Art. 49. Desconhecimento das cláusulas relativas ao uso do imóvel.

1. O juiz pode decretar de ofício a nulidade de cláusulas abusivas estipuladas em contratos abrangidos pelo Código de Defesa do Consumidor. Hipótese em que houve pedido expresso dos autores.

2. Para o efeito do exercício do direito de arrependimento previsto no art. 49 do CDC, equipara-se a contratação realizada fora do estabelecimento cometcial, aquela em que o consumidor, comparecendo em local indicado pelo fornecedor, em razão da estratégia adotada, e submetido a forte pressão psicológica que o coloca em situação desvantajosa, que o impede de refletir e manifestar livremente sua vontade. Hipótese em que o consumidor, atendendo convite por telefone, assiste a apresentação do empreendimento mediante explanações e exibição de video durante aproximadamente três horas, sendo obsequiado com coquetel, assina contrato que somente lá pode ser examinado.

3. Não obriga o consumidor o contrato celebrado, em que as cláusulas relativas ao uso do imóvel adquirido pelo sistema de tempo compartilhado constam de Regulamento que somente the foi entrehue depois da assinatura do contrato. Recurso desprovido" ${ }^{69}$

Si las nuevas normas de protección al consumidor quieren ser efectivas, en materia de contratos de time-sharing, deben asegurar a los consumidores el derecho de arrepentimiento en determinado lapso de tiempo, pues solamente de esta forma combatiremos de manera eficaz la venta emocional y los métodos agresivos de marketing usados por los proveedores de time-sharing y podremos alcanzar una voluntad realmente reflexiva, voluntad "racional" y legitimadora del consumidor de esos servicios. La buena fe así concretizada significa transparencia obligatoria en relación al co-contratante, un respeto obligatorio a los intereses normales de la otra parte, una acción positiva del contratante más fuerte para permitir al más débil las condiciones necesatias para la formación de una "voluntad racional". Así lo comprendió la jurisprudencia brasileña:

"CONTRATO DE MULTIPROPRIEDADE. Promessa de compra e venda de fração ideal 1/52 de unidade a ser construída em condomínio. Utilização por periodos anuais. Direito de arrependimento. Código de Defesa do Consumidor. Art. 49. Prática comercial agressiva.

69 Sentencia de 10 de septiembre de 1996, 9 Cámara Tribunal de Alçada do Rio Grande do Sul/ TARGS, Rel. Matia Isabel de Azevedo Souza, n. 19615299, aún no publicada. 
1. O direito de arrependimento previsto no artigo 49 do CDC tem por escopo proteger o consumidor da prática comercial agressiva que o impede de refletir e manifestar livremente sua vontade.

2. Conquanto celebrado na sede do fornecedor, e de se assegurar ao consumidor o direito de arrependimento também aos contratos cuja formulação foi antecedida de prática comercial agressiva que o coloca em situação de desequilíbrio que não le permite refletir. Hipótese em que a oferta é feita em ambiente que mais aparenta uma reunião social durante a qual o consumidor é submetido a forte pressão psicológica que enfraquece seu poder de avaliação das condições e conveniência do negócio. Recurso improvido."7h

En la Directiva Europea este derecho de arrepentimiento es de 10 días (art. 5, 1, primera hipótesis) pudiendo alcanzar hasta tres meses en caso de falla en la información al consumidor o en la redacción de los contratos de adhesión (art. 5,1, segunda hipótesis) ${ }^{71}$. El plazo de diez días parece mejor que el de sicte asegurado por el artículo 49 del CDC. Cierto es que la actuación del Ministerio Público en el control abstracto de los contratos de adhesión ha asegurado que dicho plazo sea informado al consumidor y el arrepentimiento innotivado de éste de los contratos de time-sharing sea permitido. El tesultado há sido excelente pues solamente la imposición de este plazo de reflexión y el ejercicio reiterado del derecho de arrepentimiento (inmotivado) del consumidor puede tomar el uso de los métodos de venta emocional de contratos de time-sharing obsole tos. O sea, que aún llevado por la emoción el consumidor puede pensar com calma en su casa, informarse mejor y decidir tranquilamente si desea mantener o no la obligación asumida en el impulso y la presión de las reuniones de venta, dejando sin utilidad la venta agresiva o emocional.

2. Imposición de deberes de conducta: información, cuidado y cooperación en la fase precontractual y cuidados en la redacción de los contratos al consumidor.

Para alcanzar el nivel mínimo de buena fe en todas las relaciones contractuales, yen especial en los contratos postmodernos, fluentes por excelencia y com una cadena variable de proveedores directos e indirectos de servicios y productos, el CDC brasileño resalta la existencia no solamente del deber de prestación adecuada y com calidad a cargo de los proveedores, sino también la existencia de una serie de deberes básicos de conducta que tal ordenamiento

\footnotetext{
70 Sentencia de 17 de diciembre de 1996, 9.Cámara TARGS, Rel. Maria Isabel de Azevedo Souza, N. 196233506.

${ }^{71}$ Antsblatt der $\operatorname{Eg~L~280/85,29.10.94~}$
} 
positiva $^{72}$. El CDC reglamenta así lá relación contractual en su totalidad, tanto en el momento preparatorio, donde desde ya exige deberes de conducta leal, como en su momento de ejecución. En el primero impone deberes de información clara y correcta (art. 30 y $31 \mathrm{CDC}$ ) so pena de que las informaciones mal prestadas puedan ser exigidas (art. 20 y 35 CDC), o sea que el proveedor puede tener que realizar las expectativas legitimas creadas en los consumidores por su actuación, realizar la confianza despertada.

El CDC impone el deber genérico de cuidado en las negociaciones contractuales como forma de evitar daños extrapatrimoniales al consumidor (arts. 42 a 44 CDC), por ejemplo el no divulgar datos erróneos o confidenciales sobre el consumidor. Aún en el momento preparatorio el Código impone debetes de cooperación al obligar a una redacción del contrato precisa y comprensible (art. $54, \$ 3 \mathrm{CDC}$ ) y al permitir la liberación de los consumidores caso su derecho de elección del proveedor, del servicio o del bien, o del derecho de comprensión del texto del contrato, sea obstaculizado por el proveedor (art. 46 CDC).

El deber de informar es imputado por el CDC al proveedor (caveat venditor) y no al consumidor (caveat emptor). La información debe ser adecuada y clara, por ejemplo, sobre los diferentes tipos de multipropiedad, de contratos, de servicios, de inmuebles, de apartamentos, sobre las tasas, los costos del sistema de intercambios, las verdaderas posibilidades de arrendar el inmueble o de cambiar los periodos y sobre las posibles sanciones ante el incumplimiento contractual del consumidor, las cláusulas penales y la pérdida de las garantías pagadas. La información es una obligación del proveedor de servicios y productos (arts. 30,31, 18 y $20 \mathrm{CDC}$ ) que, repito, tesponde legalmente por la actuación y promesas de sus vendedores y representantes (art. $34 \mathrm{CDC}$ ). Informar cortecta y previamente al consumidor es un deber de conducta de acuetdo com la buena fe impuesto al proveedor de servicios por el Código (art.6, inciso III c/c arts. 30 y 31 CDC), implicando nueva ejecución del servicio, redhibición o disminución en el precio pagado, dependiendo la sanción de la elección del interés del consumidor (art. 20 caput e incisos I, II y III CDC). Si el provecdor incumple su deber de informar estará, realmente, incumpliendo su obligación contractual ${ }^{13}$.

\footnotetext{
72 Estos deberes de conducta originarios de la buena fe son denominados de Nebenpflichten, deberes anexos o deberes laterales, por la doctrina alemana, ver LARENZ Karl, Schuldrecht, 1, Beck, 1991, ps 26 y sig. y COUTO E SILVA Clóvis do, A obrigaça cono processo, Bustasky, 1976, ps. 111 y sig. Quien los denomina "deberes secundarios".

${ }^{73}$ Sobre el inadiplemento de los deberes anexos o deberes laterales de conducta en los contratos ver EMMERICH Volker, Das Recht des Leistungsstörungen, 3. Ed., Beck, Munique, 1991, ps. 214 y sig., así como nuestra obra, Contratos no Código de Defesa do Consumidor, ob. cit., ps. 78 y sig
} 
En el caso de los contratos de time-sharing, donde las expectativas creadas frente al marketing agresivo, directo y, en la mayor parte de las veces, de apelo emocional en los consumidores son de dificil realización - lo que debería conducit a un cambio de los métodos de marketing utilizados por los proveedores - el CDC introduce, por norma de otden público, una garantia legal de prestación de servicios adecuados y en la cantidad necesaria para la realización de las expectativas legitimas del consumidor (arts. 24 y 25 CDC). El CDC impone, igualmente, un amplio deber de tedacción contractual precisa y comprensible (art. $54, \$ 3$ CDC) y de destaque especial para las cláusulas limitativas de los derechos de los consumidores (art. 54, $\$ 4 \mathrm{CDC}$ ) so pena de que estas cláusulas no obliguen a los mismos. La etapa de formación del contrato de time-sharing se vuelve el periodo que asegura el equilibrio del contrato futuro y donde la protección del derecho es más necesatia.

B) Ejecución del contrato de time-sharing de acuerdo com la buena fe.

\section{Ejecución contractual conforme a la confianza despertada y las expectativas legítimas}

El CDC impone, en consecuencia, la protección de la confianza despertada en el grupo de consumidores por la actuación de los proveedores y condiciona estos últimos, directa e indirectamente, a que cumplan com las obligaciones prestadas y con las promesas realizadas por sus vendedores, aunque sean autónomos, y representantes (art. 34 CDC). Ya el artículo valoriza los escritos, pre-contratos y recibos, posibilitando inclusive la ejecución específica de los pre-contratos y de las informaciones a solicitud del consumidor.

Las informaciones prestadas por los funcionarios y vendedores, por la publicidad, por los prospectos y manuales entregados, asi como por el próprio nombre del contrato, crean expectativas (ahora) consideradas legitimas, que una vez incumplidas caracterizan un inadimplemento contractual. Por ejemplo, si la calidad ofrecida, el servicio de placer prometido, el cubrimiento de determinado gasto, el atendimiento de determinada necesidad extra especificada no fuere cumplida, habrá falla en el servicio. La ejecución es defectuosa pues es menor de lo informado, de lo prometido o vehiculado. De la misma forma el contenido del contrato pasa a ser información jurídicamente relevante y el consumidor debe tener oportunidad de conocerla previamente y comprenderla (art. $46 \mathrm{CDC}$. El mismo cuidado debe ser observado en relación con las cláusulas limitativas de los derechos del consumidor. Así por ejemplo, la cláusula fijando carencias para la utilización del time-sharing, cláusulas que limitan la eficacia del contrato subordinando tal eficacia a determinado periodo de tiempo, debe ser destacada en el cuerpo del contrato como lo prevee el art. 54, $\$ 3$ del CDC, pues es una cláusula limitadora del derecho de uso inmediato (limitación en cuanto a la eficacia del contrato) y debe, principalmente, ser informada de manera previa al consumidor. Sólo con estos cuidados especiales el proveedor habrá cumplido con su nuevo deber de informar clara y adecuadamente al consumidor antes de la conclusión del contrato, asegurándole la posibilidad de escoger y comparar los planos y servicios ofrecidos en el mercado brasileño. 
La nueva relevancia de la protección de la confianza depositada por el consumidor en el tráfico jurídico en el mercado brasileño modifica de forma drástica la noción de vicio del servicio o de inadimplemento contractual parcial. Si hay falta o mala prestación, o sea, la ejecución está incompleta o es impropia, habrá inadimplemento parcial, habrá vicio en la prestación.

El CDC innova disponiendo en su att. 20 que hay vicio del servicio cuando éste no es adecuado a los fines que "razonablemente se espera de él", cuando hay disparidad entre las informaciones prestadas, que despertaron la confranza del consumidor, que lo llevaron a contratar, cuando hay disminución en la calidad y prestabilidad del servicio tornándolo impropio o disminuyendo su valor. Se trata de una novedad en relación al Código Civil brasileño que sólo conoce el vicio de la cosa y el vicio oculto. La nueva noción de vicio del servicio en el CDC fué creada para facilitar la ejecución de obligaciones de hacer (ver art. 84 CDC), tratando de materializar una falta del hacer contractual, de la prestación principal o de los deberes anexos, que acabe por frustrar las expectativas legitimas de los consumidores. En caso de vicio del servicio el consumidor podrá exigir nuevamente la ejecución del servicio o la restitución inmediata de la cuantia pagada o la rebaja proporcional del precio (art. 20 CDC).

El deber de cuidado se refiere a los cuidados doblados que los contratantes deben tener durante la ejecución, o durante los actos pteparatorios a la ejecución contractual, para no causar daño a la otra parte, por ejemplo, divulgando informaciones sobre los bienes y la condición finaciera de su colega o informaciones falsas sobre la situación financiera del consumidor conseguidas a través de un banco de datos montado por el proveedor ${ }^{74}$. Estos cuidados se refieren al patrimonio de la contraparte en el contrato, a su honra y a su crédito e imagen en la sociedad, bienes extra-patrimoniales protegidos actualmente por el derecho cuya violación hace nacer el deber de imdemnizar (art. 6 , inciso VI CDC) ${ }^{75}$.

El deber de cuidado se refiere igualmente a un deber de seguridad intrínseco a la prestación, de conformidad com la buena fe de un contrato de consumo, así el proveedor debe cuidar cuando utilice un medio técnico (por ejemplo, transporte, piscinas, complejos deportivos, cursos) que tal medio sea propio a la calidad para realizar el objeto de ocio esperado, para ejecutar su obligación de hacer de manera adecuada. La imposición de este

\footnotetext{
${ }^{74}$ Los autores portugueses denominan este deber de deber de protección, ver MENEZES DE CORDEKRO António Manuel da Rocha y, Da boa-fé no Direito Civil, Almedina, Coimbra, 1984, p. 610.

${ }^{75}$ Buen ejemplo en este sentido es el art. 42 del $\mathrm{CDC}$, donde el deber de cuidado con la contraparte contractual está positivado, exigiendo en la cobranza de deudas mayor cuidado, lealad y tespeto con el consumidor. La violación de este deber de cuidado está sancionada con la devolución en doblo de lo debido (art. 42, parágrafo único del CDC).
} 
Contratos de Time-Sharing en Brasil y a Protección de los Consumidores:

deber de cuiciado en el contrato tiene por finalidad preservar la integridad personal (moral o física) y la integridad del patrimonio de la contraparte contractual ${ }^{3}$.

El deber de cooperación es también un importante deber anexo en materia de contratos de time-sharing, una vez que tales contratos tienden a prolongarse en el tiempo, siendo la ejecución contractual no continua, renovada dependiendo de la disponibilidad del consumidor.

Ambos contratantes deben cooperar para que el co-contratante pueda cumplir, pueda realizar su prestación contractual. Así, si el consumidor debe cumplir, debe pagar las mensualidades, el valor de la cuota principal o de la administración, la empresa debe posibilitar y no impedir o dificultar ese pagamento, debe establecer horarios y locales compatibles y no elaborar exigencias sin fundamento contrarias a la buena fe, cuya tentativa es beneficiarse del eventual incumplimiento del consumidor.

De la misma manera cuando la empresa administradora está obligada contractualmente a cumplir, pernitiendo la utilización por el consumidor del time-shating, no debe por ejemplo exigir nuevos pagamentos, autorizaciones o actos no efectivamente necesarios, unicamente para impedir o desmotivar al consumidor a exigir aquel tipo de prestación contratada, en aquel momento y aceptar cambiarlo por otro. Actuando de esta manera estará violando su deber anexo de cooperación, deber de buena fe, estará cumpliendo mal, inadecuadamente y el consumidor podrá exigir sus expectativas legítimas frente al vicio del servicio (arts. 20 y 35 CDC).

El CDC establece en sus artículos 18 y 20 una responsabilidad solidaria de la cadena de proveedores por el buen cumplimiento de la obligación contractual. Esta solidaridad presumida de toda la cadena de proveedores podrá ser utilizada para solicitar la suspensión del pagamento de las boletas de cartas de crédito usadas para garantizar el pagamento futuro del time-sharing, caso el consumidor quiera rescindir el contrato, o el inadimplemento por parte de los proveedores esté siendo discutido en juicio.

Teniendo en vista la garantía legal de prestación de servicios adecuados y de la calidad, que el CDC introduce por norma de orden público en sus artículos 24 y 25 , garantía esta mínima y que no podrá sex excluída por cláusulas contractuales, las normas del CDC acaban por alcanzar toda la cadena de proveedores relacionada, directa o indirectamente, en la satisfacción de las expectativas legitimas contractuales de los consumidores. Como lo mencionamos anteriormente, cl CDC impone una nueva protección de la confianza despertada en el grupo de consumidores por la actuación de los proveedores, al forzar a los proveedores relacionados directa o indirectamente con contratos de time-sharing a cumplir con las informaciones prestadas y con las promesas hechas por sus vendedores, aun cuando éstos sean autónomos, y sus representantes. El art. 34 CDC establece una solidaridad entre el proveedor, que contrató con el consumidor y sus vendedores, aun cuando autónomos.

\footnotetext{
${ }^{7}$ Ver detalles sobre el deber de cuidado en nuestro Contratos, ob. cit., ps. 87 y sig.
} 


\section{La interpretación pro consumidor de las cláusulas contractuales y el control del contenido del contrato.}

El contrato de time-sharing ofrecido en el mercado debe especificar cual es la naturaleza de los derechos (reales u obligacionales) asegurados al consumidor. La interpretación de las cláusulas contractuales y del contrato en su totalidad debe - ex vilege - ser siempre a favor del consumidor (art. $47 \mathrm{CDC}$ ).

La posición contractual preponderante (Machtposition) que se refleja en la clabonación de las reglas contractuales y en la ejecución del contrato, así como el reconocimiento de la vulnerabilidad fáctica, técnica y económica del consumidor (art. 4, inciso I CDC) llevaron at legislador del CDC a establecer un control del contenido del contrato, de su equilibrio interno, de manera a garantizar la justicia contractual y la realización de las expectativas legitimas del consumidor en el mercado brasileño. Se trata de una protección a posteriori, pero el próprio CDC prevee la posibilidad de un control judicial en abstracto (art. 51, 4 CDC), sobre la iniciativa del Ministerio Público, de manera a suplir la falta de un control administrativo previo de las cláusulas contractuales, control éste vetado por el Presidente de la República en el momento de la promulgación del CDC.

La masificación y proliferación de los contratos de time-sharing en Brasil, la inexistencia de legislación específica reglamentando el contenido de esos contratos, así cono el esporádico control ejercido por los órganos oficiales en lo que se refiere a las condiciones generales contractuales impuestas, permitieron e inclusive incentivaron la inclusión en este tipo de contrato de una serie de cláusulas consideradas actualmente abusivas.

Entre las cláusulas que han despertado el nayor número de reclamaciones y disputas están la cláusula penal, la cláusula de pérdicla de cuantías pagadas, la cláusula mandato, la cláusula de elección del fuero, la cláusula de vencimiento anticipado de los débitos, la cláusula que permite la rescisión unilateral por el proveedor del contrato, las cláusulas de carencia o de limitación de los derechos de uso, las cláusulas que permiten la variación del precio y las cláusulas que limitan la utilización de servicios conexos al complejo de placer.

Estas cláusulas desequilibran el contrato, violan la confianza despertada en el consumidor, impiden la realización de sus expectativas legitimas de un cumplimiento adecuado y previsible por parte del organizador del time-sharing en el futuro. El CDC no contiene una definición legal de lo que se considera abusivo, prefiriendo sea indicar el abuso en casos expresos (art. $53 \mathrm{CDC}$ sobre el abuso de la cláusula de pérdida total de las prestaciones pagadas); sea dejar su deteminación en el caso concreto a la jurisprudencia, fijando apenas una cláusula general (art. 51, inciso VI CDC sobre la cláusula general de buena fe); sea elaborando una lista de ejemplos de cláusulas abusivas y de conductas comerciales abusivas (listas de los arts. 5 y 39 CDC). El sistema del CDC trae, en consecuencia, una prohibición genérica de la inclusión de cláusulas abusivas en los contratos de time-sharing.

Como lo destaca Hélène Bricks, las cláusulas abusivas presentan justamente como carcterísticas comunes su fin y su efecto. El fin común de las cláusulas abusivas sería la 
mejoría de la situación contractual de aquel que redacta el contrato o detiene una posición contractual preponderante, el proveedor, transfiriendo asi al consumidor riesgos que normalmente deberia soportat, de acuetdo com el derecho supletivo. El efecto común de las cláusulas abusivas es el desequilibrio del contrato en razón de su inclusión o de la falta de reciprocidad y unilateralidad de los detechos asegurados a través de la cláusula al proveedor ${ }^{77}$.

Según Antôni Janyr Dall'Agnoll Jt. lá nujidad de las cláusulas abusivas prevista en el sistema del CDC (art. 51 caput) es una nulidad absoluta. El Magistrado se apoya en el sistema tradicional brasileño de nulidades, donde las nulidades previstas expresamente en ley o a través de prohibiciones legales directas, son nulidades absolutas ${ }^{78}$ si no se especifica nada en contrario. Efectivamente el caput del art. 51 del CDC dispone que son "nulas de pleno derecho" las cláusulas abusivas previstas en contratos envolviendo el aprovisionamiento de bienes o servicios en el mercado para consumidores, sean contratos de adhesión o contratos discutidos individualmente ${ }^{79}$.

De otro tado, la nulidad absoluta de los arúculos 51 a 53 del CDC ha permitido a los jueces, en la práctica, declarar la nulidad de las cláusulas ex officio, pero mantener la relación contractual. Este es el espíritu del art. 51 \& del CDC que, imponiendo el concepto de continuidad de la relación, establece la obligatoriedad de la tentativa de integración del texto del contrato y su mantenimiento por el magistrado, caso después de la declatación de nulidad de la cláusula el contrato no imponga onerosidad excesiva para ninguno de los dos contratantes. La jurisprudencia ha visto en esta noma una autorización para reducir la eficacia de la cláusula nula, teoria, sin embargo, bastante discutible ${ }^{8 *}$.

Finalmente vale la pena mencionar que el carácter abusivo de las cláusulas puede estar en el desequilibrio general de la ingeniería contractual y no en su texto, si este fuere examinado de forma aislada. La interpretación de estas cláusulas y su declaración como abusivas dependerá, en consecuencia, de su inclusión en el texto del contrato, en aquella relación contractual específica, en aquel tipo de contrato de consumo. En este sentido vale repetir lo dispuesto en el art. 3 de la Directiva 93/13 de la Comunidad Europea: "las cláusulas contractuales que no

\footnotetext{
"Bricks, Hélène, Les clauses abusives, LGDJ, Paris, 1982, pg. 8

${ }^{7 R}$ Dall'Agnoll, Anónio Janyr Jr, Cháusulas Abusivas: A opçăo brasileira, in: Estudos sobre a prote Hão do consumidor no Brasil e no Mercosul, Claudia Lima Marques (Coord.), Ed. Livraria dos Advogrados, Porto Alegre, 1994, P. 38. Ver, defendiendo mi opinión que las aulidades del CDC nulidades con caracteristicas especiales setian, por tratarse de un microsistema autónomo, Nery, Nesson Jr., in: Código de Defesa do Consumidor- Comentários dos Autores do Anteprojeto de Lei, Forense, 1991, p. 298.

7) Ver Aguiar, Ruy Rosado de Jr., Cláusulas Abusivas no Código do consumidor, in: Estudos sobre a proteção do consumidor no Brasil e no Mercosul, Claudia Lima Marques (Coord.), Ed. Livraria dos Astrogados, Porto Alegre, 1994, p. 20. El autor defiende, sin embatgo, una cienta diferenciación en la lista ejemplificativa del art. 51, concluyendo que el tégimen es casi semejante al alemán, de cláusulas nulas y cláusulas donde la valorización es positiva (Jista negra y gris).

8:) Ver mi opinión contraria y argumentos de la jurisprudencia, en nuestro libro Contratos,ob. cit., ps. $297 y$ sig.
} 
se hayan negociado individualmente se considerarán abusivas si, frente a las exigencias de la buena fe, causan en detrimento del consumidor un desequilibrio importante entre los derechos y obligaciones de las partes que derivan del contrato. ${ }^{8:}$

\section{Consideraciones Finales}

Sin querer traer ninguna conclusión en sentido estricto es posible afirmar que la protección asegurada en el CDC al consumidor de servicios de time-sharing no alcanzó aún el nivel ideal en Brasil. Los instrumentos jurídicos ya están a disposición de los aplicadores de la ley y el cambio más importante fué la introducción de un nuevo paradigma en el relacionamiento contractual entre proveedores y consumidores: la protección de la confianza, que impone una conducta de conformidad con la buena fe objetiva en todas las etapas de la relación negocial, inclusive en la fase pre-contractual. En la formación de los contratos de time-sharing una nueva autonomía de la voluntad del consumidor debía ser impuesta, una autonomía racional, de fortna a combatit los métodos abusivos y emocionales de ventas hoy utilizados. El contrato de multipropiedad o de time-sharing presenta una serie de riesgos para el consunidor y se caracteriza como un contrato cautivo de larga duración, un contrato múltiple y fluente, un contrato postmoderno que exige una respuesta de la ciencia del derecho para limitar y regular la libertad de establecer las cláusulas contractuales y un mejor control judicial del contenido y del desequilibrio de estos contratos.

Repetimos lo que afirmaba el Juez Schimasky de la Corte Federal Alemana en un artículo de doctrina sobre la autonomía de la voluntad, al defender que la libertad contractual es una norma general de protección de la dignidad de las personas y debe protegerse esta libertad, "Sin embargo no podemos proteger la libertad contractual de aquel que quiere justamente reducir, limitar o aún excluir la libertad contractual de la otra parte. Libertad es siempre la libertad del otro". El Magistrado de la más alta corte civil alemana destaca que el contrato es "por esencia bilateral, la libertad contractual es en consecuencia indivisible, ella significa la libertad de los dos y no solamente la libertad del contratante más fuerte" ${ }^{82}$. En este sentido las técnicas de limitación de la voluntad del contratante más débil en materia de contratos de time-sharing, como las técnicas de venta emocional, no deben ser menospreciadas por el derecho, al contrario él debe editar normas especiales que se tornen instrumentos de protección de la voluntad "libre" y presumida del consumidor.

${ }^{81}$ Publicada en el JOCE L $95 / 31$ de 21.4.93.

${ }^{82}$ Schimansky, Hebert, Bankvertragsrecht und Privatautonomie, in: WM- Zeitschrift für Wirtschafts- und Bankrecht (Frankfurt), Nr. 11, 18.03.95, p. 461-467(462 et.463). 